\title{
Онтологический смысл японского понятия "тама" (дух): герменевтический анализ хроники "Кодзики"
}

В японской культуре наиболее раннее объяснение мира и места в нем человека было сформировано в рамках мифопоэтического синтоистского мировоззрения, отдельные элементы которого не утратили свою актуальность и на сегодняшний день. Мы понимаем мифр как структуру мышления, которая образно формирует и выражает представления о мире и тем самым указывает и на первоначальные онтологические установки, присущие такому мировоззрению.

Источником нашего исследования являются три древних свитка "Кодзики", в которых последовательно изложены мифологические и исторические сюжеты, повествующие о появлении мира, божествах и их деяниях и первых императорах. Можно сказать, что японская культура уже изначально мыслила себя исторически, т.к. практически любое повествование строится по хронологическому принципу; а основная тенденция таких повествований, прослеживаемая в первых мифрах синто, - это постоянное указание на связь и непрерывную линию, проводимую между божествами и человеком.

Выбор источника данного исследования мотивирован так же и тем, что для крупнейшего интерпретатора синто Мотоори Норинага (1730-1801) "Кодзики" является текстом, в котором сохранилось древнее мировоззрение в наиболее подлинном виде, т.к. язык написания в большей мере соответствовал японскому. Норинага считал, что именно через раскрытие значения "древнего слова" "Кодзики" мы сможем исследовать процесс формирования японского мышления [15].

Одна из особенностей синтоистского мировосприятия состоит в том, что оно не содержит привычного для западного мышления представления о божественном как о нечто трансцендентном, но буквально указывает на постоянное присутствие божественного в сфере сакрального, стирая между ними границу. О том же пишет и А.Н. Мещеряков, утверждая, что "синтоизм интересует по преимуществу определение человека лишь в его отношении к божествам. Таким образом, сфера его применения ограничена и актуализируется только в строго определенном "ритуальном" пространстве и времени" [9, с. 155]. Так мы обнаруживаем, что в синтоистском мировоззрении в известной степени нивелируется разница между священным и профанным, но акцентируется присутствие "духовного" в каждом явлении и вещи.

Возвращаясь к "Кодзики", еще раз отметим, что в этом памятнике описывается и связь человека с нечеловеческим, в том числе и с божественным. Это "божественное" в "Кодзики" выражено несколькими понятиями в общем и целом переводимыми как "дух" или "душа": 1) древнеяпонское понятие $m u$, которое, судя по всему, заложило наиболее древний слой представлений о божественном, но уже в "Кодзики" утратило полнозначность и фригурирует лишь как часть теонимов (примерно такое же происхождение у суфффикса ицу и префикса $м и) ; 2$ ) исследуемое нами понятие тали, имеющее наиболее высокий после ти онтологический статус; 3) наиболее широко известное понятие кали, которое чаще всего и сопоставляется с западными концепциями божеств; так же в этот ряд можно поставить 4) понятие моно, присущее природным объектам или силам; и 5) духов предков ларэбито 賓人 $[4$, с. 25; 16, с. 266]. При исследовании представлений о божественном в синтоистской мифологии, об-

(C) Завертан Д. А., 2021

ЗАВЕРТАН Дарина Алексеевна, магистрант Дальневосточного федерального университета (2. Владивосток). E-mail: darina.zavertan@gmail.com 
наруживается, что из множества видов "духов", наиболее важным и лежащим в основе онтологических установок древнего синто является понятие тала.

В "Энциклопедии синто" Э.В. Молодяковой предложено следующее определение [1, с. 142]: "Тама 霊 - душа, дух, сгусток "живого", концентрация духовной энергии, которая является источником жизни. Тала присуща всей природе, поскольку она рождена, а не сотворена божественной парой. Чем больше накапливается духовной энергии, тем сильнее становится тала и, соответственно, ее обладатель". Т.П. Григорьева определяет тала как ощутимую жизненность, как то, что "создает все вещи" [3, с. 38].

Размытость понятия тала связана с тем, что со временем оно было вытеснено понятием кали, а его употребление в разы сократилось, почти сойдя на нет. А. Соболева подмечает, что ритуалы, основанные на идее тама, сохраняют магические элементы, но при этом несколько изменяют свое значение, сливаясь с представлениями о кали. Изначально ориентированные на манипуляции магической силой тала, эти обряды превращаются в коммуникацию с душой божества кали. Она делает вывод, что постепенно идея кали сливается с идей тала через ритуалы, и образуется плотный комплекс верований и ритуалов, который и становится ядром синтоизма [11].

Т.П. Григорьева указывает на значение тали как одновременно и души, и Духа: единичное и Единое [2, с. 207]. Так, тала одновременно то, что есть во всем, и то, к чему все причастно. Важную особенность тали выделяет А.А. Накорчевский, она "бестелесная независимая субстанция", способная отделить себя от человека или вещи, которой она присуща, т.к. наличие или отсутствие в теле талиа не является признаком жизни каким является дыхание [10, с. 84]. Таким образом, присутствие тала означает нечто отличное от простой жизненности: оно означает некую причастность к миру, хорошим примером чего может быть представление о котодала (дух слова - яп.) как медиуме коммуникации и пространства [8, с. 190].

В "Кодзики" понятие тала является одним из наиболее трудных для интерпретации, т.к. оно сопротивляется дефиниции из-за своего функционирования в довольно разнородных контекстах. Как бы то ни было, наша установка заключается в том, что, хоть понятие тала исторически и ушло "на задний план", оно остается ключевым для понимания исконного японского мировоззрения и представлений о божественном, свойственным этому мировоззрению.

В тексте хроники мы обнаруживаем четыре варианта употребления понятия тали, которые выражаются разными иероглифрами и демонстрируют разные грани одного широкого понятия тала:

1) знак 霊 (靈), понимаемый нами как "[порождающий] Дух";

2) знак 玉, понимаемый нами как "[ценный] дар";

3) знак 珠, понимаемый нами как "жемчужина";

4) знак 魂, понимаемый нами как "душа".

Анализ текста позволил нам подкрепить наши доводы о многогранности понятия тала и продемонстрировать его функциональное значение как нечто взаимосвязывающего все сущее.

В данном исследовании использована методология герменевтического анализа иероглифических текстов и употребляемых в них философрских категорий другой культуры, разработанная Д.В. Конончуком [7] совместно с методологией герменевтического прочтения древнеяпонских текстов, предложенной Ивасава Томоко [15], и ориентированной на интерпретацию религиозного опыта древней Японии.

Чтобы подтвердить вышесказанное, проанализируем случаи употребления четырех вариантов тали в тексте "Кодзики". Таблица 1 демонстрирует вариативность и частотность употребления иероглифов, обозначающие понятие тала:

Исходя из таблицы, можно обнаружить некоторые закономерности. Прежде всего, очевидно, что частотность употребления понятия тама снижается, однако это объясняется тем, что 2-й и 3-й свитки являются дворцовой летописью. То есть если 1-й свиток - это космогонические мифы, то остальные два - хроника преемственности власти и "житие" государей Ямато, поэтому мы допускаем отсутствие или сокращение онтологических понятий, в нашем случае - понятия тама. Ещё одна закономерность заключается в том, что 
Таблица 1. Частотность употребления иероглифов, выражающих понятие тама в «Кодзики»

\begin{tabular}{|l|c|c|c|c|c|}
\hline & Всего & $\begin{array}{c}\text { 霊 } \\
(\text { (дух }\end{array}$ & $\begin{array}{c}\text { 玉 } \\
\text { (дар) }\end{array}$ & $\begin{array}{c}\text { 珠 } \\
\text { (жемчужина) }\end{array}$ & $\begin{array}{c}\text { 魂 } \\
\text { (душа) }\end{array}$ \\
\hline 1-й свиток & 71 & 14 & 34 & 16 & 7 \\
\hline 2-й свиток & 26 & 1 & 21 & 1 & 3 \\
\hline 3-й свиток & 13 & 2 & 10 & 1 & 0 \\
\hline $\begin{array}{l}\text { Кол-во знаков на } \\
\text { 1000 в 1-м Свитке }\end{array}$ & $\approx 4,25$ & $\approx 0,84$ & $\approx 2,04$ & $\approx 0,95$ & $\approx 0,42$ \\
\hline $\begin{array}{l}\text { Кол-во знаков на } \\
\text { 1000 во 2-м свитке }\end{array}$ & $\approx 1,41$ & $\approx 0,05$ & $\approx 1,14$ & $\approx 0,05$ & $\approx 0,16$ \\
\hline $\begin{array}{l}\text { Кол-во знаков на } \\
\text { 1000 в 3-м Свитке }\end{array}$ & $\approx 1,14$ & $\approx 0,17$ & $\approx 0,87$ & $\approx 0,09$ & $\approx 0$ \\
\hline
\end{tabular}

Источник: составлено автором.

количество употреблений тала, как "дара" и "жемчужины", превалирует над количеством употреблений в качестве "духа". В этой связи мы выдвинем гипотезу о том, что такое употребление не случайно и прежде всего свидетельствует о том, что выбор иероглифа чаще всего обуславливается его контекстуальной уместностью. Например, иероглиф 玉 чаще всего используется в составе имен божеств, когда другой иероглиф 珠 со сходным значением жемчужины используется в тексте только в утилитарном значении эмпирического предмета. Чтобы проследить обусловленность выбора каждого иероглифа, рассмотрим варианты их фрункционирования в тексте.

\section{Анализ первого свитка "Кодзики"}

\section{霊 (靈)-талма как "[порождающий] дух"}

Мы полагаем, что употребление тала в значении "порождающий дух" является наиболее значимым и близким к его изначальному смыслу. В тексте "Кодзики" данное значение записывается иероглифом 霊, который встречается достаточно редко, в частности в начале "Предисловия Ясумаро", написанного составителем хроники, лишь единожды:

Я говорю, Ясумаро: В те времена, когда Хаос уже начал сгущаться, но ещё не были явлены ни Силы, ни Формы, и не было ещё ничему Имени, и ни в чем Деяния, кто мог бы тогда познать его образ? Но вот настало впервые разделение Неба-Земли, и три божества совершили почин творения; и раскрылись мужское и женское Начала, и Два Духа (二靈) стали родоначальниками всех вещей [6, с. 29] ${ }^{1}$.

Данный отрывок - это некий пересказ начала повествования "Кодзики" о трех первобожествах и породившихся от них божественных супругах Идзанаги и Идзанами, которые являются "родоначальниками всех вещей". Этот контекст и "диктует" выбор иероглифа 霊 (靈) для записи тала в значении порождающего духа и указания на связь земного и небесного.

Когда впервые раскрылись Небо и Земля, имена богов, явившихся в Такама-но хара - Равнину Высокого Неба, были: Амэ-но-минака-нуси-но ками - Бог-Правитель Священного Центра Небес; за ним Така-ми-мусуби-но ками (高御產巢日神) - Бог Высокого Священного Творения; за ним Камимусуби-но ками (神產巢日神) - Бог Божественного Творения. Эти три бога явились каждый сам по себе и не дали себя увидеть [6, с. 38].

При анализе понятия тала в теонимах "Кодзики" мы обнаруживаем, что оно раскрывается нам как некая божественная (священная) порождающая связь.

1 Здесь и далее текст "Кодзики" цитируется по изданиям: [5; 6] . Иероглифические примечания в скобках - наши, цит. по [13]. 
Как следует из имени первого божества, оно является владыкой Неба и, следовательно, всего возникающего мира. Однако, несмотря на эту, казалось бы, центральную роль, оно появляется всего единожды только в этол вступительнол фбрагменте и никогда не уполинается в остальной части текста.

В отличие от таинственной роли первого божества, следующие два божества воплощают мусуби (или мусухи), главный принцип японской космогонии. Имя одного из указанных выше первобогов, Така-ли-лусуби-но-кали, на современном японском языке записывается как 高皇産霊神, где бином лусуби 産霊, содержащий в себе иероглиф 霊, а само слово лусуби в широком смысле обозначает "связь".

Читаем далее:

Имя за ней из мочи явившейся богини [было] Мицуха-но-мэ-но ками - Богиня Бегущих Вод, следующее Вакумусуби-но ками (和久產巢日神 (иначе 産霊) Молодой Бог Творящих Сил. Дитя этого бога зовется Тоёукэ-бимэ-но ками - Дева-Богиня Обильной Пищи [6, с. 44].

В ещё одном теониме, где иероглифы используются для фонетической записи слова мусуби, Е. М. Пинус переводит их как "творящая сила" в теониме Вакулусуби-но кали (Молодой Бог Творящих Сил, то или божество плодородия, роста злаков). В этом имени слово мусуби используется в значении "творить", "порождать". Такой же смысл вкладывается и при переводе других двух теонимов: Така-ли-лусуби-но кали (Бог Высокого Священного Творения) и Калилусуби-но кали (Бог Божественного Творения).

Ранее упомянутая Ивасава Томоко, разъясняя смысл понятия мусуби [14, c. 101], пишет, что японское слово мусуби состоит из двух корней: мусу и би. Mycy - это глагол, который в первую очередь означает "возникнуть" (яп. мусу 生寸), а также "родить" (яп. мусу 産す). Это же слово используется в значении "приготовить на пару" (яп. мусу 蒸す), и оно же связано с понятием "дыхание" (яп. мусу 息). Таким образом, можно говорить, что слово мусу предлагает изначальный образ постоянного про-из-ведения бытия. Второй же корень, входящий в состав мусуби, т.е. слово би (или $x u$ ) илиеет различные значения, такие как "солнце" (яп. $x u$ 日), "огонь" (яп. $x u$ 火) и "божественная сила", записываемая рассматриваемым нами иероглифом 霊, который в японском языке также имеет чтение $x и$. Таким образом, мы можем понимать мусуби как божественную силу, "про-из-водящую бытие", т.е. как образ, лежащий в основе того, как японское мифическое сознание понимало бытие (яп. ару 有る). То есть бытие означает про-явление, в процессе которого что-то сокрытое-возможное стало явленным-действительным (яп. ару 現る), а лусуби - это жизненная сила, пронизывающая все про-явленное.

\section{玉 - тама как "[ценный] дар"}

Иероглифр 玉, буквально означающий некий драгоценный камень, оказался самым частым вариантом для записи слова тала. Однако это употребление обуславливается не всегда единообразно, и можно отметить зависимость от смыслового контекста:

Исикоридомэ-но микото - Богине-Литейщице наказали изготовит зеркало, Тама-но-я-но микото (玉祖命) - Богу-Предку Гранильщиков наказали изготовить длинную нить со множеством [нанизанных] магатама (八尺勾之 五百津之御須麻流之珠), призвали Амэ-но-коянэ-но микото - Бога Возносящего и Футодамано микото (布刀玉命) - Бога Приносящего и заставили [их] у оленя-самца небесной горы Кагуяма вывернуть лопатку, взять небесное дерево Хахака с небесной горы Кагуяма и исполнить гадание [6, с. 56].

Данный отрывок демонстрирует использование иероглифа в двух теонимах. Tали-но-я-но ликото 玉祖命 (Бог-Предок Гранильщиков), где иероглифр талиа 玉 означает драгоценный камень, который и поддается огранке. E.M. Пинус объясняет это тем, что иероглифр я 祖 имеет значение "лицо" и обозначает род деятельности, т.е тали-но-я - это ювелир-предок гранильщиков драгоценных камней. В теониме Футодалано ликото 布刀玉命 (Бог Приносящий) иероглиф тала (дала) имеет значение "духа" и, возможно, "драгоцен- 
ности", однако такой перевод основан на предположении японского фрилософра Мотоори Норинага о том, что этот теоним - это сокращение от ритуала $m a$ макуси, т.е. подношения божествам ветки священного дерева сасаки, т.к. в повествовании божество выполняет жреческие функции - поднесение даров.

Обратим внимание на продолжение этого текста:

Густоветвистые деревья Масакаки с небесной горы Кагуяла, выкопав с корнями, к верхним веткам прикрепили длинные нити со множеством маramana (八尺勾璁之五百津之御須麻流之玉), на средние ветки навесили большущее зеркало, к нижним веткам подвесили белые, голубые лоскуты нигитэ, и все эти различные вещи бог Футодалиа-но микото (布刀玉命) благоговейно, для преподношения [богине Аматэрасу], держал, а бог Алэ-но коянэ-но микото сильное молитвословие благоговейно вознес [6, с. 56].

Употребление иероглифра тала 玉 здесь обнаруживается в том же теониме, о котором мы писали выше, но ещё один иероглифр используется в словах "длинная нить со множеством магатама" (八尺勾璁之五百津之御須麻流 之玉), но что любопытно, в предыдущем отрывке в этом же сочетании используется другой иероглир тала, а именно 珠 (cp. 八尺勾之五百津之御須麻流之 珠). Мы наблюдаем в этом определенную закономерность: во втором случае сам предмет "длинная нить со множеством магатама" (八尺勾璁之五百津之御 須麻流之玉) является подношением, в то время как в первом - это пока ещё просто предмет, который "наказано изготовить". Это ещё раз указывает на многогранное значение тала, которое действительно обуславливается смысловым контекстом "Кодзики".

\section{珠-талиа как "жемчужина"}

При анализе иероглифа тала 珠, как было сказано выше, наблюдается лишь "утилитарное" значение, т.е его употребление в значении реальной жемчужины как предмета (сл. Таблииа 1).

Наиболее наглядно это демонстрируют следующие отрывки:

Тут бог Идзанаги-но микото, сильно обрадовавшись, сказал: "Я детей рождал-рождал, и напоследок трех высоких детей получил", - так сказал и тут же снял с шеи ожерелье из жемчужин (御頸珠之玉) и, тряся его так, что звенели [они], передал [его] Великой Священной Богине Аматэрасу оо-миками и сказал: "Ты, богиня, ведай Равниной Высокого Неба", - так ей наказал. Потому ожерелье то из жемчужин (御頸珠) зовется Микуратанано-но ками - Бог Священного Хранилища [6, с. 51].

В обоих случаях в иероглифическом написании слов "ожерелье из жемчужин" (御頸珠) для слова жемчужина используется иероглиф 珠, но в первом случае употребления добавляется иероглиф тала 玉 (御頸珠之王). Это объясняется смысловым контекстом: когда божество подносит ожерелье богине, оно становится даром божества. Во втором же случаем ожерелье лишь именуется как обычный предмет, не акцентируясь на его божественном происхождении, и поэтому иероглиф 玉, указывающий на дарственность, не пишется.

Ещё один пример употребления жемчужины-тала 珠:

Если [он] на то, что [ты] так сделал, разгневается и на тебя нападать станет, [ты] Жемчужину Прилива (御頸珠) вынь и [его] утопи, если на это горевать-жаловаться станет, [ты] Жемчужину Отлива (鹽乾珠) вынь и его оживи, - вот так [его] мучай-терзай", - так сказав, Жемчужину Прилива (鹽盈 珠)- Жемчужину Отлива (鹽乾珠), обе вместе [ему] пожаловал [6, с. 93].

Можно подумать, что Жемчужины Прилива и Отлива тоже являются даром божеств, однако, дело в том, что в этом сюжете "Кодзики" акцент делается на некие "рекомендации" к действиям, а не на повествование о божественных дарах, поэтому используется утилитарный иероглиф талма 珠.

魂-талма как "душа"

Обусловленностью такого варианта иероглифического написания мы находим в понимании тала как духовной сущности или такой души, представление о которой с известными оговорками близко к западному пониманию. Рассмотрим на примерах из текста: 
И вот, когда тот бог Саруда-хико-но кали пребывал в Адзака, [он] ловил рыбу, и раковина хирабу заглотнула [его] руку, [потому он] погрузился в воду и утонул. Потому по имени он, когда погрузился на дно, Сокодоку-ми-тама ( 底度久御魂) - Священный Дух, Достигший Дна, зовется; по имени он, когда на морской воде пузырьки пены появились, Цубутацу-ми-тама (都夫多 都御魂) - Священный Дух Вскипающих Пузырьков Пены зовется; по имени он, когда пена обильно запузырилась, Авасаку-ми-тама (阿和佐久御魂)Священный Дух Образующейся Пены зовется [6, с. 87].

Употребление этого иероглифра в тексте "Кодзики" достаточно редкое, и чаще всего встречается как элемент теонима, например, митали 御魂 "Священный Дух", и только в связке с другим иероглифом .ми 御 "священное" (этот же иероглифр используется в теонимах первобогов, что было указано выше, например, Така-ли-лусуби-но кали - Бог Высокого Священного Творения).

Однако митала 御魂 встречается не только в именах божеств, но и единожды как самостоятельное слово, выражающее дух божества, с которым возможно дальнейшее общение-поклонение:

Тут [богиня Алатэрасу богу Хикохо-но-ниниги дала] длинные нити со множеством магатала, зеркало - те, которыми [ее из грота] выманивали, а ещё меч Кусанаги, а ещё Токоё-но-олоиканэ-но ками - Бога Размышляющего из Вечного Царства, Бога-Мужа Тадзикара-о-но кали, Алэ-но-ивато-вакэ-но кали - Юного Бога Небесного Скалистого Входа присоединила и сказала: "Это зеркало полностью считай моим духом ( 御魂), поклоняйся ему так, как мне поклонялся бы. А бог Олоиканэ-но кали пусть примет [на себя] мои дела [на земле] и управляет", - так сказала [6, с. 85].

\section{Анализ второго свитка "Кодзики"}

Иероглиф 霊 "дух" встречается в тексте лишь однажды, и то в составе имени императора: Государь Ко:рэй (孝靈天皇), где иероглиф читается на китайский манер. Другие два иероглифа со значением "жемчужина": тала 玉 как драгоценность и талиа 珠 как сфера. Второй вариант встречается один раз в этом отрывке:

И вот, предметы, которые Амэ-но пибоко перевез через море были: того, что зовут сокровищем-жемчужиной (玉) - два драгоценных сокровища (珠) [5, c. 96].

Здесь непросто определить причину выбора иероглифов и их перевод, но можно заметить, как пересекаются понятия "жемчужины" и "драгоценности" как дара и как сокровища (утилитарное значение).

Обратимся к употреблению тала 玉 как жемчужины-драгоценности, которую мы определили выше как "дар" божеств: в большом отрывке повествуется о красной жемчужине, выраженной тала 玉, которую родила женщина от солнечного луча, т.е имеется в виду ее божественное происхождение. Из этой жемчужины появилась прекрасная дева, которая из-за недолжного к ней отношения вернулась "в страну своих предков". Этот отрывок также демонстрирует то, что, когда речь идет о даре богов, используется иероглиф 玉, в этом мы находим подтверждение о том, что тала есть нечто связующее между богами и человеком.

Tали как "душа" 魂 встречается в этом свитке три раза. В начале свитка - как имя меча:

Этому мечу имя - Сазитуто-но ками, а ещё одно имя - Путо-но митама (御 魂). Этот меч пребывает в храме Исоноками [5, с. 37].

Под этим именем меч почитается в храме Исонокали в области Ямато, в качестве "сокровища" - магического предмета, служащие для усмирения души императора [5, с. 109] . Далее:

И если нынче в самом деле помышлять о завоевании той страны, то надлежит принести дары всем-всем божествам неба, божествам земли, а ещё 
божествам гор, а также божествам рек и морей, нашу душу священную (御 魂) на ладью поместить, в тыкву вложить пепел священного дерева, во множестве палочки для еды и плоские блюда изготовить и пустить все это плавать по морю великому, а уж после этого переход по морю совершать", - так рекли [5, с. 82].

Этот отрывок представляет пример общения с божествами, связи человека и божеств. Здесь описано преподношение "высшим силам" для удачного похода. Особый интерес вызывает "вложение души", т.е. важно обратить внимание на то, что в данном контексте тали определяется как священная душа, необходимая для диалога с божественным.

Третий раз тали 魂 употребляется в тексте как грубая душа (аралитама) великого божества Сулиноё (即以墨江大神之荒御魂).

Каждый отрывок демонстрирует, что 魂, всегда в связке митала 御魂, в тексте выражает духовную составляющую божества и человека.

\section{Анализ третьего свитка "Кодзики"}

Тала как "душа" 魂 ни разу не встречается в третьем свитке, но рассмотрим другие употребления понятия тала:

Государь [Кэнзо:] сильно возненавидел государя Опопатусэ, который убил его отца-принца. Он решил отомстить духу (靈) покойного [5, с. 207].

В данном отрывке тала 霊 переводиться как "дух покойного", что кардинально отличается от предыдущих примеров употребления данного иероглифа в тексте. Однако стоит упомянуть, что иногда в современном японском языке употребление иероглифов 霊 и 魂 аналогичны и, например, употребляются в словосочетании литала как 御霊 и как 御魂 т.е. "дух умершего предка, душа". Как раз слиянием понятий, выраженных одухотворенностью тала, стиранием их границ, мы объясняем такое различие между употреблением их в свитках.

Иероглиф 玉 в третьем свитке употребляется 10 раз: в составе теонима, в названии дворца, в словосочетании, которое переводят как "драгоценная корона" и как "жемчужный", сделанный из жемчуга, например:

Затем они убежали оттуда и когда прибыли в Сони, что в Уда, войска настигли их и убили. Полководец Ямабэ-но Опотатэ-но Мурази снял жемчужный браслет (玉釧) с руки Мэдори-но Опокими и отдал его своей жене [5, c. 178].

Иероглиф тала 珠 как "жемчужина" употребляется в привычном нам утилитарном смысле как жемчужины-бусины:

Его младший брат - Мидупа Вакэ-но Микото - пребывал во дворце Сибакаки, что в Тадипи, и правил Поднебесной. Росту в нем было девять сяку и два с половиной суна. Зубы у него были длиной в один сун, а шириной - в два кида. Верхние и нижние [зубы] были одинаковы и походили на жемчужины (珠) в ожерелье [5, с. 183].

В целом в третьем свитке "Кодзики" мы не только наблюдаем употребление иероглифов в их буквальном значении, но и еще раз обнаруживаем глубокий смысловой контекст для выбора понятий и конкретные закономерности. Однако, и напротив, мы можем заметить размывание смысловых границ понятий, выраженных тала, что подтверждает нашу гипотезу о том, что со временем понятие тала действительно утрачивает свое первоначальное значение порождающей и связующей мир сущности, т.к. повествование переходит хронологически от времени божеств ко времени людей.

Таким образом, в результате проведенного анализа употребления различных вариантов написания понятия тала, обнаруживается четыре варианта написания иероглифа тала, представляющих собой единый семантический комплекс. Проанализировав примеры употребления иероглифов тала в тексте "Кодзики" и усмотрев смысловой контекст каждого, мы теперь можем более точно определить функциональные значения понятия тала, применив әкзистенциальную схему, предложенную С.Е. Ячиным. 
Согласно данной схеме, существование человека, его экзистенция, проявляется в его возможности вступать в четыре разных отношения к миру: отношение к предметному (окружающему) миру, к Другому, к своей собственной телесности, и к трансцендентному [12, с. 6]. Будучи выраженным в четырех иероглифах, грани понимания тала соотносятся с указанными четырьмя отношениями причастности к миру:

1. Тали 霊 - как причастность всеобщему (порождающий дух);

2. Тали 魂 - как самость (душа); ность);

3. Тала 玉 - как причастность другому посредством дара (драгоцен-

4. Tалиа 珠 - как причастность миру (жемчужина).

Наличие представлений о тала в философрском смысле позволяет говорить о том, что уже на ранних этапах формирования японского мировоззрения Мир характеризуется отсутствием разграничения между феноменальным и онтологическим. Именно совокупность связей и указание всех вещей друг на друга конституирует Мир, в понимающем отношении к которому и находится человек так же будучи бытием-в-мире. Тала раскрывается перед нами как универсальное онтологическое понятие, опосредующее фундаментальную взаимооткрытость бытия и человека.

\section{Литература}

1. Боги, святилища, обряды Японии: энциклопедия синто : Orientalia et Classica: Труды Института восточных культур и античности / ред. И.С. Смирнов. М.: РГГУ, 2010. Вып. 26. 210 с.

2. Григорьева Т.П. Япония: путь сердца. М.: Культурный центр "Новый Акрополь", 2008. 388 с.

3. Григорьева Т.П. Японская художественная традиция. М.: Главная редакция восточной литературы издательства "Наука", 1979. 368 с.

4. Ермакова Л.М. Культы и верования в раннем периоде японской культуры / Синто - путь японских богов: Очерки по истории синто: в 2 т. СПб.: Гиперион, 2002. T. 1. C. 7-42.

5. Кодзики - Записи о деяниях древности. Свитки 2-й и 3-й / Пер., предисл. и коммент. Л. М. Ермаковой, А. Н. Мещерякова: Литературный памятники древней Японии. II. СПб.: ШАР, 1994. 256 с.

6. Кодзики - Записи о деяниях древности. Свиток 1-й. Мифы / Пер., коммент. Е. М. Пинус : Литературный памятники древней Японии. СПб.: ШАР, 1993. 320 с.

7. Конончук Д.В. Константы конфуцианской культуры: к методологии вопроса // История как фундамент гуманитарного познания. К 100-летию исторического образования на Дальнем Востоке: материалы международного семинара, 15-17 октября 2018 г. / ред. кол.: Ф. Е. Ажимов, П. Г. Добмаев, Б. И. Пружинин, Т. Г. Щедрина. Владивосток: Изд-во Дальневост. федерал. ун-та, 2018. С. 32-42.

8. Матвеенко В.А. О душе слов: герменевтика как способ японского миропонимания // Вестн. Том. гос. ун-та. Философия. Социология. Политология. 2016. № 4 (36). C. $184-194$.

9. Мещеряков А.Н. Древняя Япония: культура и текст. М.: Наука, Главная редакция восточной литературы; Академия наук СССР, Институт Востоковедения, 1991. 224 c.

10. Накорчевский А.А. Синто: Мир Востока. СПб: Азбука-Классика, Петербургское Востоковедение, 2003. 448 с.

11. Соболева А. Взаимосвязь концептов "тама" и "ками" в контексте исторической трансформации синто // Окно в японию, [Электронный ресурc]. URL: http:// ru-jp.org/ soboleva_01.htm (дата обращения: 04.12.2020).

12. Ячин C.Е. Аналитика человеческого бытия: введение в опыт самопознания. Систематический очерк. М.: ИНФРА-М, 2014. 217 с.

13. Кодзики дзэнбунґ古事記全文」(Полный текст "Записей о деяниях древности") // Seisaku, [Электронный ресурc]. URL: http:// www.seisaku.bz/kojiki_index.html (дата обращения: 04.12.2020).

14. Iwasawa T. Philosophical Implications of Shintō // The Oxford Handbook of Japanese Philosophy / Edited by Bret W. Davis. 2015. P. 97-110.

15. Iwasawa T. Tama in Japanese Mith. A Hermeneutical Study of Ancient Japanese Divinity. Maryland: University Press Of America, 2011. 180 p.

16. Miller R.A. The "Spirit" of the Japanese Language // The Journal of Japanese Studies. 1977. Vol. 3, no. 2. P. 251-298. 


\section{Транслитерация по ГОСТ 7.79-2000 система Б}

1. Bogi, svyatilishha, obryady YAponii: ehntsiklopediya sinto : Orientalia et Classica: Trudy Instituta vostochnykh kul'tur i antichnosti / red. I.S. Smirnov. M.: RGGU, 2010. Vyp. 26. $210 \mathrm{~s}$.

2. Grigor'eva T.P. YAponiya: put' serdtsa. M.: Kul'turnyj tsentr "Novyj Akropol"', 2008. 388 s.

3. Grigor'eva T.P. YAponskaya khudozhestvennaya traditsiya. M.: Glavnaya redaktsiya vostochnoj literatury izdatel'stva "Nauka", 1979. 368 s.

4. Ermakova L.M. Kul'ty i verovaniya v rannem periode yaponskoj kul'tury / Sinto - put' yaponskikh bogov: Ocherki po istorii sinto: v 2 t. SPb.: Giperion, 2002. T. 1. S. 7-42.

5. Kodziki - Zapisi o deyaniyakh drevnosti. Svitki 2-j i 3-j / Per., predisl. i komment. L. M. Ermakovoj, A. N. Meshheryakova: Literaturnyj pamyatniki drevnej YAponii. II. SPb.: SHAR, 1994. 256 s.

6. Kodziki - Zapisi o deyaniyakh drevnosti. Svitok 1-j. Mify / Per., komment. E. M. Pinus : Literaturnyj pamyatniki drevnej YAponii. SPb.: SHAR, 1993. $320 \mathrm{~s}$.

7. Kononchuk D.V. Konstanty konfutsianskoj kul'tury: k metodologii voprosa // Istoriya kak fundament gumanitarnogo poznaniya. K 100-letiyu istoricheskogo obrazovaniya na Dal'nem Vostoke: materialy mezhdunarodnogo seminara, 15-17 oktyabrya 2018 g. I red. kol.: F. E. Azhimov, P. G. Dobmaev, B. I. Pruzhinin, T. G. SHHedrina. Vladivostok: Izd-vo Dal'nevost. federal. un-ta, 2018. S. 32-42.

8. Matveenko V.A. O dushe slov: germenevtika kak sposob yaponskogo miroponimaniya // Vestn. Tom. gos. un-ta. Filosofiya. Sotsiologiya. Politologiya. 2016. № 4 (36). S. 184-194.

9. Meshheryakov A.N. Drevnyaya YAponiya: kul'tura i tekst. M.: Nauka, Glavnaya redaktsiya vostochnoj literatury; Akademiya nauk SSSR, Institut Vostokovedeniya, 1991. $224 \mathrm{~s}$.

10. Nakorchevskij A.A. Sinto: Mir Vostoka. SPb: Azbuka-Klassika, Peterburgskoe Vostokovedenie, 2003. $448 \mathrm{~s}$.

11. Soboleva A. Vzaimosvyaz' kontseptov "tama" i "kami" v kontekste istoricheskoj transformatsii sinto // Okno v yaponiyu, [Ehlektronnyj resurs]. URL: http:// ru-jp.org/ soboleva_01.htm (data obrashheniya: 04.12.2020).

12. YAchin S.E. Analitika chelovecheskogo bytiya: vvedenie v opyt samopoznaniya. Sistematicheskij ocherk. M.: INFRA-M, 2014. 217 s.

13. Kodziki dzehnbun「古事記全文」(Polnyj tekst "Zapisej o deyaniyakh drevnosti") // Seisaku, [Ehlektronnyj resurs]. URL: http:// www.seisaku.bz/kojiki_index.html (data obrashheniya: 04.12.2020).

14. Iwasawa T. Philosophical Implications of Shintō // The Oxford Handbook of Japanese Philosophy / Edited by Bret W. Davis. 2015. P. 97-110.

15. Iwasawa T. Tama in Japanese Mith. A Hermeneutical Study of Ancient Japanese Divinity. Maryland: University Press Of America, 2011. 180 p.

16. Miller R.A. The "Spirit" of the Japanese Language // The Journal of Japanese Studies. 1977. Vol. 3, no. 2. P. 251-298. 
Завертан Д. А. Онтологический смысл японского понятия "тама" (дух): герменевтический анализ хроники "Кодзики'"'.

В данной работе автор предпринимает попытку посредством герменевтического анализа древнего текста "Кодзики" эксплицировать комплексное понимание древнеяпонского понятия тама и реконструировать его исходное значения как нечто связующего мир. В работе понятие тала рассматривается не в качестве мифического понятия, связанного с религиозным комплексом древнего синто, а как онтологический элемент, связанный с представлениями о сопричастности взаимной открытости Мира и человека. Проводя анализ мифов "Кодзики", автор обнаруживает, что понятие тама выражается четырьмя омонимичными функциональными оттенками, обозначенными разными иероглифами, примеры употребления и смысл которых также раскрывается в работе.

Ключевые слова: тала, синто, японская фбилософия, Кодзики, фбилософия мифба, герменевтика

Zavertan D. A. A hermeneutic explication of the ontological meaning of the Japanese philosophical concept "tama" (spirit) on the example of the "Kojiki'"'.

The paper attempts to explicate a synthetic understanding of the Japanese concept of tama through a hermeneutical analysis of the ancient text of the Kojiki to reconstruct its original meaning as something that ties and organizes the World. In the article, the concept of tama is considered not as a mythical concept associated with the religious complex of ancient Shinto, but as an ontological element associated with the idea of involvement and mutual openness of the World and human being. Analyzing the myths of "Kojiki", the author discovers that the concept of tama is expressed in four homonymous functional shades, indicated by different hieroglyphs, examples of usage and the meaning of which are also revealed in the work.

Key words: Tama, Shinto, Japanese philosophy, Kojiki, Philosophy of myth, Hermeneutics

Для цитирования: Завертан Д. А. Онтологический смысл японского понятия "тама" (дух): герменевтический анализ хроники "Кодзики"'" // Ойкумена. Регионоведческие исследования. 2021. № 2. С. 155-164. DOI: 10.24866/1998-6785/2021-2/155-164

For citation: Zavertan D. A. A hermeneutic explication of the ontological meaning of the Japanese philosophical concept "tama" (spirit) on the example of the "Kojiki"' // Ojkumena. Regional researches. 2021. № 2. P. 155-164. DOI: 10.24866/1998-6785/2021-2/155-164 